\title{
Clinical, Echocardiographic Characteristics and Management Practices in Patients with Rheumatic Valvular Heart Disease
}

This article was published in the following Dove Press journal: Open Access Rheumatology: Research and Reviews

\section{Temesgen Mulugeta (D) \\ Kabaye Kumela \\ Legese Chelkeba (DD}

Department of Clinical Pharmacy, Institute of Health, Jimma University, Jimma, Oromia, Ethiopia
Correspondence: Temesgen Mulugeta Department of Clinical Pharmacy, Institute of Health, Jimma University, P. O Box: 378, Jimma, Oromia, Ethiopia Tel +25 I 917734764

Email temesgen.mulugeta@ju.edu.et
Background: Rheumatic heart disease (RHD) is the long-term consequence of acute rheumatic fever (ARF), continues unabated among middle-income and low-income countries. Thus, this study aimed to assess clinical characteristics, echocardiographic characteristics, and management practice of RHD patients.

Methods: Hospital-based prospective cross-sectional study was used. The data were collected from medical records of consecutive patients admitted to medical wards during the study period. The data were cleaned and analyzed using SPSS version 20. Descriptive statistics were used to describe the data. Chi-square was used to compare proportions between categorical variables.

Results: Forty-seven patients with a median (IQR) age of 28.0 (17.0-40.0) years were included. Pan systolic murmur was reported in $91.50 \%$ of patients. Forty-two $(89.4 \%)$ of patients were presented with congestive heart failure and $23(48.9 \%)$ with atrial fibrillation. Mitral valve leaflet thickening and calcification with restriction of motion were reported in $91.5 \%$ of patients. Mitral regurgitation (MR) (87.2\%) and stenosis (MS) (85.1\%) were the most common valvular lesions. The combinations of three (MR+MS+TR) $14(29.8 \%)$ and four (MR+MS+TR+AR) $13(27.7 \%)$ valve diseases were most commonly reported. Diuretics $(95.7 \%)$, anticoagulants $(38.3 \%)$, digoxin $(36.2 \%)$, and beta-blockers $(34.0 \%)$ were among the commonly prescribed medications.

Conclusion: Rheumatic heart disease affected younger adults. Pansystolic murmur was reported in nearly all patients. Congestive heart failure and atrial fibrillation were common clinical presentations. Morphologic changes in mitral valve and pathologic mitral regurgitation were the most common echocardiographic reports. Cardiovascular medications were commonly utilized for symptomatic management of complications Therefore, echocardiography should be done routinely for patients with RHD, focusing on younger adults, to facilitate diagnosis and treatment before complications develop.

Keywords: rheumatic heart disease, clinical characteristics, echocardiography, management

\section{Background}

In 2015 , there were 33.4 million cases of rheumatic heart disease and 10.5 million disability-adjusted life years due to rheumatic heart disease globally. The death due to rheumatic heart disease was $319,400{ }^{1}$ In contrast to the developed nations, where the valvular disease is largely degenerative, in Africa it is almost always the result of infectious disease, either directly, as in infective endocarditis, or indirectly, as in acute rheumatic fever. Acute rheumatic fever and chronic rheumatic valvular disease in their most virulent form are still commonly encountered and 
impose a considerable burden on limited healthcare resources. $^{2}$ Traditionally, RHD was diagnosed by auscultating for a heart murmur in those with a history of ARF. However, the detection rates were usually low. ${ }^{3}$ Echocardiography plays a critical role in the diagnosis of rheumatic valve disease, allowing objective monitoring of the severity of valve lesions, LV chamber size, LV function, and an increase in pulmonary artery pressure. ${ }^{4}$

In the REMEDY study, rheumatic heart disease patients were young, predominantly female, and complicated by congestive heart failure (33.4\%), pulmonary hypertension (28.8\%), atrial fibrillation (AF) $(21.8 \%)$, stroke $(7.1 \%)$, infective endocarditis (4\%), and major bleeding (2.7\%). One-quarter (25\%) of adults and $5.3 \%$ of children had decreased left ventricular (LV) systolic function; $23 \%$ of adults and $14.1 \%$ of children had dilated LVs. There was a higher use of medications such as oral anticoagulants (69.5\%), diuretics (67.8\%), b-blockers $(39.3 \%)$, digoxin $(34.7 \%)$, and other antiarrhythmic drugs $(1.6 \%) .^{5}$

A study done in western Kenya showed the most common valvular involvement was a combination of mitral and aortic valves (51\%) followed by mitral valves alone $(38 \%)$. The most common concurrent cardiac diagnoses were arrhythmia (20\%), systolic heart failure (19\%), and infective endocarditis (7\%). ${ }^{6}$ In Uganda, rheumatic heart disease remains a leading cause of progressive and severe primary left-sided valve disease. It disproportionately affected the young, productive age groups. It was a major risk factor for infective endocarditis. ${ }^{7}$

In Ethiopia, valvular heart disease, which was predominantly rheumatic heart disease was the most common primary diagnosis in $62.0 \%$ of 3282 cardiac patients. It predominantly caused heart failure in $81 \%{ }^{8}$ An earlier retrospective study (between January 1994 and January 1995) from Gondar showed, among 114 RHD patients with a median age of 22 years (range $=5-50$ years), females were predominant. The frequently encountered valve lesions were combined mitral regurgitation and stenosis seen in $29(25.4 \%)$, followed by pure mitral stenosis in $25(21.9 \%)$ and mitral regurgitation in $21(18.4 \%)$. The commonest arrhythmia was atrial fibrillation, observed in $22.8 \%$ of the cases. Recurrence of rheumatic fever occurred in 11 patients $(9.6 \%)$. Drug discontinuation was one of the most common precipitating factors followed by infection. ${ }^{9}$ With a high burden of rheumatic heart disease in developing countries, it is important to understand the patterns of valvular lesions and its impact on cardiovascular morbidity. Therefore, this study was aimed to assess the clinical and echocardiographic characteristics as well as the management of patients with rheumatic heart disease.

\section{Methods}

\section{Study Area}

The study was conducted at Jimma medical center (JMC), a tertiary hospital in Jimma city, Jimma zone, Oromia regional state, Southwest Ethiopia; which is 352 kilometers away from Addis Ababa. Jimma is the largest city in south-western Ethiopia. JMC is one of the referral hospitals for the Southwest population of the country. The hospital provides service to 15 million people with 1600 staff members, 32 intensive care units, and 800 beds. $^{10}$

\section{Study Design and Period}

A hospital-based prospective cross-sectional study was carried out for 5 consecutive months between April 10 and September 10, 2019.

\section{Study Participants}

All consecutive patients aged 15 years and above admitted to a medical ward within the study period and diagnosed to have a rheumatic heart disease confirmed by echocardiography imaging were included. Valvular heart diseases other than rheumatic causes were excluded.

\section{Echocardiography Reports}

The report on transthoracic echocardiography was according to the standard format developed by the American Society of Echocardiography 1) Demographic and other identifying information, 2) Echocardiographic (Doppler) evaluation and 3) Summary. ${ }^{11}$ Ordering of echocardiography was left to the physician treating the patients after clinical suspicion. Patients underwent a standard transthoracic echocardiogram according to the 2014 AHA/ACC guideline for the management of patients with valvular heart disease. ${ }^{12}$ Rheumatic VHD was diagnosed based on the 2012 World Heart Federation (WHF) criteria for echocardiographic diagnosis of definitive RHD. ${ }^{3}$ Classification of the severity of valve disease was reported from Doppler echocardiography as mild, moderate, and severe based on indicators mentioned in the 2008 ACC/AHA Focused Update Practice Guideline Guidelines for the Management of Patients with Valvular Heart Disease. ${ }^{13}$ 


\section{Data Collection Tool and Procedures}

The data collection tool was developed after reviewing different relevant literature, institutional guidelines, and patient follow-up charts. The tool was changed to the local language (Afan Oromo and Amharic) and then translated back to English. Before starting data collection, a pretest was conducted on eligible patients already in the ward, and then the tool was modified accordingly. Data were collected by reviewing the patient's medical record. The data collected included patient's socio-demographics, echocardiography reports, current diagnoses, and medications. The data collection was carried out by trained two ward-based clinical nurses and supervised by two medical residents and a principal investigator. The collected data was checked appropriately for completeness, accuracy, and consistency. The incomplete data was returned to the data collector and revised.

\section{Ethical Consideration}

Ethical clearance (a reference number, IHRPGJ/652/2019) was obtained from the Institutional Review Board (IRB) of Jimma University Institute of Health. Written informed consent was obtained before the review of the patient's record. Confidentiality of their personal information was kept and assured through the use of codes as an identifier.

\section{Statistical Analysis}

The data were entered and cleaned using Epidata 3.1 version and transferred to SPSS version 20 for analysis. The normality of variables was checked with the ShapiroWilk test. Categorical variables were described in number and percentage, and continuous variables in mean with SD or median with interquartile range. Chi-square (2) was used to compare proportions between categorical variables. A p-value $<0.05$ was considered statistically significant.

\section{Result}

\section{Sociodemographics}

A total of 47 RHD patients were included. Females accounted for $53.2 \%$ of the participants. The median (IQR) age of patients was $28.0(17.0-40.0)$ years.

\section{Clinical Characteristics}

On auscultation, 43 patients had pan-systolic murmur, of which 23 patients had grade 3, 16 had grade 4, and 2 patients had grade 5 . In $53.2 \%$ of patients, their systolic
Table I Patterns of Presentation with Major Cardiovascular Events

\begin{tabular}{|l|l|l|l|}
\hline $\begin{array}{l}\text { Serial } \\
\text { number }\end{array}$ & $\begin{array}{l}\text { Cardiovascular } \\
\text { Events }\end{array}$ & Frequency & Percentage \\
\hline 1 & $\begin{array}{l}\text { Congestive heart } \\
\text { failure }\end{array}$ & 42 & 89.4 \\
2 & Atrial fibrillation & 23 & 48.9 \\
3 & Atrial thrombus & 7 & 14.9 \\
5 & Infective endocarditis & 5 & 10.6 \\
4 & Pulmonary edema & 4 & 8.5 \\
6 & Stroke & 3 & 6.4 \\
7 & Rheumatic & 3 & 6.4 \\
& recurrence & & \\
\hline
\end{tabular}

murmurs heard at apex followed by $25.5 \%$ at both apex and left lower sternal border. Systolic murmurs radiated to the axilla in $48.9 \%$ of patients. And 26 patients had a diastolic murmur where 10,5 , and 4 patients had grades 3,4 , and 2 respectively. Diastolic murmurs heard at the apex in $27.7 \%$ of patients followed by at left lower sternal border $(10.6 \%)$ and right upper sternal border (10.6\%).

Patients presented with congestive heart failure $89.4 \%$, atrial fibrillation $48.9 \%$, atrial thrombus $14.9 \%$, infective endocarditis $10.6 \%$, pulmonary edema $8.5 \%$, stroke $6.4 \%$, and rheumatic recurrence $6.4 \%$. [Table 1]. Twenty-nine (61.7\%) of patients had pulmonary hypertension. Among 13 patients with pulmonary hypertension, the mean right ventricular systolic pressure (RVSP) was 66.65 $\pm 23.86 \mathrm{mmHg}$. In $21.3 \%$ of patients, pneumonia had precipitated the condition. Small pericardial effusion was reported in 6 patients. The median (IQR) erythrocyte sedimentation rate for 24 patients was $40.0(20.25,77.5)$ $\mathrm{mm} / \mathrm{hr}$.

\section{Echocardiographic Characteristics Morphological Features}

Mitral valve leaflets thickening and calcification with restriction of motion has occurred in $91.5 \%$ of rheumatic heart disease patients. Thickening and calcification of aortic cusps occurred in $53.2 \%$ of patients, while the thickening of the tricuspid valve occurred in $14.9 \%$. Both the mitral and aortic valve, and mitral valve alone were involved in $40.4 \%$ of patients respectively.

\section{Pathological Valve Lesions}

Mitral regurgitation (87.2\%) and mitral stenosis (85.1\%) were the most common valvular lesions in RHD patients. Aortic stenosis and pulmonary regurgitation were the least 
common. In 16 patients, the mean (SD) regurgitant jet velocity (Vmax) was 3.64 \pm 0.64 meter/second. Male patients had a higher percentage of mitral regurgitation and aortic regurgitation compared to females $(100.0 \%$ vs. $76.0 \%)$ and (68.2\% vs $32.0 \%)$ respectively. Most of the mitral stenosis (MS) was severe, which was reported in $46.8 \%$ of patients [Table 2].

In 31 patients with mitral stenosis, the median (IQR) mitral valve area measured in planimetry was $1.25 \mathrm{~cm}^{2}$ $(0.50,2)$. Even though it was insignificant, a higher number of females had mitral stenosis compared to the male (92.0\% vs.77.3\%, $\mathrm{P}=0.228)$. Most of the patients had a combination of three valvular diseases. The combination of $\mathrm{MR}+\mathrm{MS}+\mathrm{TR}$ and $\mathrm{MR}+\mathrm{MS}+\mathrm{TR}+\mathrm{AR}$ was the most common and reported in $14(29.8 \%)$ and $13(27.7 \%)$ of patients respectively. The other combinations were rarely reported. In 35 patients, the mean (SD) left ventricular ejection fraction was $48.50 \pm 14.82 \%$.

\section{Dimensional Parameters}

Measurement of left atrial diameter, left ventricular diameter (left ventricular internal diameter during diastole and systole), right atrial, and ventricular diameter was

Table 2 Patterns of Valvular Lesions of Rheumatic Heart Disease Patients $(\mathrm{N}=47)$

\begin{tabular}{|l|l|l|l|l|}
\hline $\begin{array}{l}\text { S. } \\
\text { No }\end{array}$ & Valvular Lesions & N (\%) & Severity & N (\%) \\
\hline I & $\begin{array}{l}\text { Mitral regurgitation } \\
(\text { MR) }\end{array}$ & $\begin{array}{l}4 I \\
(87.2)\end{array}$ & $\begin{array}{l}\text { Severe } \\
\text { Moderate } \\
\text { Mild }\end{array}$ & $\begin{array}{l}15(31.9) \\
14(29.8) \\
6(12.8)\end{array}$ \\
\hline 2 & Mitral stenosis (MS) & $\begin{array}{l}40 \\
(85.1)\end{array}$ & $\begin{array}{l}\text { Severe } \\
\text { Moderate } \\
\text { Mild }\end{array}$ & $\begin{array}{l}22(46.8) \\
6(12.8) \\
4(8.5)\end{array}$ \\
\hline 3 & $\begin{array}{l}\text { Tricuspid regurgitation } \\
(\text { TR) }\end{array}$ & $\begin{array}{l}36 \\
(76.6)\end{array}$ & $\begin{array}{l}\text { Severe } \\
\text { Moderate } \\
\text { Mild }\end{array}$ & $\begin{array}{l}14(29.8) \\
8(17.0) \\
9(19.1)\end{array}$ \\
\hline 4 & $\begin{array}{l}\text { Aortic regurgitation } \\
(\text { AR) }\end{array}$ & $\begin{array}{l}23 \\
(48.9)\end{array}$ & $\begin{array}{l}\text { Severe } \\
\text { Moderate } \\
\text { Mild }\end{array}$ & $\begin{array}{l}7(14.9) \\
8(17.0) \\
6(12.8)\end{array}$ \\
\hline 5 & Aortic stenosis (AS) & $3(6.4)$ & $\begin{array}{l}\text { Severe } \\
\text { Moderate } \\
\text { Mild }\end{array}$ & $\begin{array}{l}\text { I (2.1) } \\
2(4.3)\end{array}$ \\
\hline 6 & $\begin{array}{l}\text { Pulmonary } \\
\text { regurgitation (PR) }\end{array}$ & $3(6.4)$ & $\begin{array}{l}\text { Severe } \\
\text { Moderate } \\
\text { Mild }\end{array}$ & $\begin{array}{l}\text { I (2.1) } \\
2(4.3)\end{array}$ \\
\hline
\end{tabular}

Notes: $N=$ frequency, \%: percentage (-): not reported. reported. The measurement of left atrial diameter was reported in 25 patients. The mean (SD) value was 5.61 $\pm 1.77 \mathrm{~cm}$, which was relatively increased compared to the standard range $(2-4 \mathrm{~cm})$. The mean values of others were within the normal range of their standard values. [Table 3].

\section{Management Practices}

Nearly all RHD patients (95.7\%) were prescribed diuretics. Anticoagulants (38.3\%), digoxin (36.2\%), and betablockers $(34.0 \%)$ were among the commonly prescribed medications. Antibiotics were prescribed for 23 patients including for bacterial infective endocarditis. The proportion of patients who had mitral stenosis were prescribed angiotensin-converting enzyme inhibitors less than those who do not have MS (17.5\% vs $57.1 \%, \mathrm{P}=0.042)$. However, relatively more patients who had MS were prescribed anticoagulants than those patients who do not have MS (42.5\% vs $14.3 \%, \mathrm{P}=0.225)$. Two patients who presented with rheumatic recurrence were treated with prednisolone alone and the remaining one patient with prednisolone and aspirin. Atorvastatin was prescribed for three patients who had a cardioembolic stroke. [Table 4]

\section{Discussion}

In this study, RHD patients were younger and more than half were females. The median age was 28 years and females accounted for $53.2 \%$ of the patients. The finding was like the large multicenter REMEDY study, ${ }^{5}$ where the median age of RHD patients was 28 years and $66.2 \%$ of the patients were females. However, the newly diagnosed RHD patients in the Oceanic populations had a lower median age of 18 years. ${ }^{14}$ This difference might be due to patients enrolled in our study included both new and old diagnoses of RHD and small sample size.

Concerning valvular murmur, the majority of the patients reported having a pan systolic murmur upon auscultation. This is in accordance with a review by Jennifer E Frank and his colleagues, ${ }^{15}$ where they described red flags that increase the likelihood of a pathologic murmur included holosystolic or diastolic murmur, grade 3 or higher murmur.

The majority of the patients were presented with congestive heart failure which accounted for $89.4 \%$ of the presentation. This is slightly higher when compared to a study by Mirabel et al, ${ }^{14}$ where about $78.30 \%$ of RHD patients were admitted with congestive heart failure. However, it is much higher compared to the study done in Uganda, ${ }^{16}$ where $46.3 \%$ of patients at a time of 
Table 3 Cardiac Chambers Dimension

\begin{tabular}{|l|l|l|}
\hline Chambers & $\begin{array}{l}\text { Number } \\
\text { of } \\
\text { Patients }\end{array}$ & $\begin{array}{l}\text { Mean } \\
\mathbf{E S D}\end{array}$ \\
\hline $\begin{array}{l}\text { Left atrial diameter }(\mathrm{cm}) \\
\text { Left ventricular internal diameter during } \\
\text { diastole }(\mathrm{cm})\end{array}$ & 25 & $\begin{array}{l}5.61 \pm \mathrm{I} .77 \\
5.41 \pm \mathrm{I} .16\end{array}$ \\
$\begin{array}{l}\text { Left ventricular internal diameter during } \\
\text { systole }(\mathrm{cm})\end{array}$ & 22 & $3.94 \pm \mathrm{I} .2 \mathrm{I}$ \\
$\begin{array}{l}\text { Right atrial diameter }(\mathrm{cm}) \\
\text { Right ventricular diameter }(\mathrm{cm})\end{array}$ & 4 & $\begin{array}{l}4.8 \pm 0.23 \\
3.82 \pm 0.55\end{array}$ \\
\hline
\end{tabular}

Abbreviations: $\mathrm{cm}$, centimeter; SD, standard deviation.

presentation had heart failure of any stage. In this study, $48.9 \%$ of patients were presented with atrial fibrillation. However, at a time of presentation, $20.3 \%$ of patients had atrial fibrillation in Uganda. ${ }^{16}$ The difference might be related to increased left atrial diameter and atrial fibrillation, which is higher in our study. Cardiac thrombus was reported in $14.9 \%$ of patients, however, it was not reported in a study by Okello et al. ${ }^{16}$ However, it was reported in $2.3 \%$ of patients in a study by Sani et al. ${ }^{17}$

Regarding morphological features, thickening and calcifications of mitral valve leaflets were the most common. Yadeta et $\mathrm{al}^{18}$ from Ethiopia also reported among 44 definite RHD children, 39 of them had mitral regurgitation (MR) with two morphological features.

Regarding valvular lesions, mitral regurgitation was the most frequently reported valve disease. Our finding was supported by Okello et al ${ }^{16}$ and Mirabel et al, ${ }^{14}$ Sani et $\mathrm{al}^{17}{ }^{17}$ and Aurakzai et $\mathrm{al}^{19}$ where they reported mitral regurgitation, the most common echocardiography finding.

Table 4 Medications Prescribed

\begin{tabular}{|l|l|l|}
\hline Medications & Frequency & Percentage \\
\hline Diuretics & 45 & 95.7 \\
Antibiotics & 23 & 48.9 \\
Anticoagulants & 18 & 38.3 \\
Digoxin & 17 & 36.2 \\
Beta-blockers & 16 & 34.0 \\
Angiotensin-converting enzyme & 11 & 23.4 \\
inhibitors & & \\
Aspirin & 4 & 8.5 \\
Prednisolone & 3 & 6.4 \\
Atorvastatin & 3 & 6.4 \\
\hline
\end{tabular}

Notes: Acid suppressants (8), Ferrous sulfate (5), Analgesics (4), ART (3), anti-TB (2), $\mathrm{KCl}$ (2), Plasil (2), dopamine (I), PTU (I), Albendazole (I), phenytoin (I), amlodipine (I), insulin (I), calcium gluconate (I).

Abbreviations: ART, antiretroviral therapy; anti-TB, anti-Tuberculosis; $\mathrm{KCl}$, potassium chloride; PTU, propylthiouracil.
Similarly, aortic stenosis was the least commonly reported by both authors, Mirabil et al, ${ }^{14}$ Okello et al. ${ }^{16}$ Males had a higher number of mitral and aortic regurgitation compared to females. However, this finding contradicts what Aurakzai et $\mathrm{al}^{19}$ found, where aortic regurgitation was more common in females. For patients with mitral stenosis (MS), the median (IQR) mitral valve area was $1.25 \mathrm{~cm}^{2}$ $(0.50,2)$. This is comparable to a study done by Tadele et al from Ethiopia, where the mean mitral valve area was $1.1 \pm 0.5 \mathrm{~cm}^{2.20}$ Pulmonary hypertension was reported in $61.7 \%$ of patients. This is lower compared to the study by Lubega et al, ${ }^{21}$ which was found in $77.4 \%$ of RHD children. The difference might be because of patients included in a study by Lubega et al were children aged $\leq 15$ years. Similarly, secondary pulmonary hypertension was observed in $72.1 \%$ of RHD patients in Nigeria, ${ }^{17}$ which was slightly higher compared to this study.

In this study, most of the patients had a combination of three valvular diseases. Combined MR+MS+TR and MR $+\mathrm{MS}+\mathrm{TR}+\mathrm{AR}$ were the most common and reported in 14 (29.8\%) and 13 (27.7\%) of patients respectively. Similar to our findings, Aurakzai et al ${ }^{19}$ reported three valves were involved in $21.06 \%$ of patients. Our finding is also supported by a study by Tadele et al, ${ }^{20}$ where multi-valvular involvement was present in $90.4 \%$ of RHD patients. However, Sani et $\mathrm{al}^{17}$ from Nigeria reported a combination of MR+MS was the most common, reported in $29 \%$ of patients.

Pneumonia was one of the precipitating medical conditions in $21.3 \%$ of RHD patients. However, an earlier retrospective study by Melka et $\mathrm{al}^{9}$ reported drug discontinuation was the most common precipitating factor. The difference might be due to the patients were retrospectively included in the study by Melka et al. ${ }^{9}$ Additionally, Wood et $\mathrm{al}^{22}$ reported rheumatic mitral valve disease (RMVD) was associated with an increased risk of pneumonia $(\mathrm{OR}=(2.00[1.81-2.20]))$. In patients who were diagnosed before the current admission, rheumatic recurrence was documented in $6.4 \%$ of patients. This is slightly comparable to a study by Melka et al, ${ }^{9}$ where it was $9.6 \%$.

Concerning the management of RHD patients, all patients were managed with medical therapy because there was no interventional therapy. The medications most frequently prescribed were diuretics $(95.7 \%)$, anticoagulants (38.3\%), digoxin (36.2\%), and beta-blockers $(34.0 \%)$ were among the commonly prescribed medications. Zulke et $\mathrm{al}^{5}$ reported oral anticoagulants (69.5\%), 
diuretics (67.8\%), beta-blockers (39.3\%), and digoxin (34.7\%), were highly utilized in RHD patients. However, in our study, diuretics were mostly prescribed because most of the patients were presented with heart failure.

\section{Limitation}

The major limitation of this study was a lack of complete echocardiographic data and a small sample size of patients. Being a cross-sectional in design and lack of follow-up data was another limitation of this research.

\section{Conclusion}

In this study, rheumatic heart disease affected younger adults. Pansystolic murmur was reported in nearly all patients. The majority of rheumatic heart disease patients were presented with a diagnosis of congestive heart failure and atrial fibrillation. Morphologic changes in mitral valve leaflets and pathologic mitral regurgitation were the most common echocardiographic reports. Cardiovascular medications were regularly utilized for symptomatic management of complications, since there was no surgical intervention in the study area. Therefore, echocardiography should be performed routinely for patients with rheumatic heart disease, focusing on younger adults, to facilitate diagnosis and treatment before complications develop.

\section{Abbreviations}

RHD, rheumatic heart disease; ARF, acute rheumatic fever; MR, mitral regurgitation; MS, Mitral stenosis; TR, tricuspid regurgitation; AR, aortic regurgitation; AS, aortic stenosis; $\mathrm{PR}$, pulmonary regurgitation; IQR, interquartile range; $\mathrm{SD}$, standard deviation; cm, centimeter; mm, millimeter; JMC, Jimma Medical Center; AHA/ACC, American Heart Association/American College of Cardiology.

\section{Data Sharing Statement}

The investigators will provide data to allow for the replication of study procedures upon reasonable request to the corresponding author.

\section{Ethics Approval and Consent to Participate}

Ethical clearance was obtained from the Ethical Review Board of Jimma University. The ethics approval was given in accordance with the Declaration of Helsinki. Patients were requested for written informed consent and confidentiality of the patients' was maintained. For patients under
18 years old, written informed consent was obtained from a parent or guardian.

\section{Acknowledgments}

The authors of this study would like to acknowledge Jimma Medical Center for allowing us to conduct this study. We also thank all study participants, data collectors, and clinicians working in the medical wards of the Jimma medical center.

\section{Author Contributions}

All authors contributed to data analysis, drafting or revising the article, have agreed on the journal to which the article will be submitted, gave final approval of the version to be published, and agree to be accountable for all aspects of the work.

\section{Disclosure}

The authors declare that they have no competing interests.

\section{References}

1. Watkins DA, Johnson CO, Colquhoun SM. Global, regional, and national burden of rheumatic heart disease, 1990-2015. $N$ Engl $J$ Med. 2017;377(8):713-722. doi:10.1056/NEJMoa1603693

2. Essop MR, Nkomo VT. Rheumatic and nonrheumatic valvular heart disease epidemiology, management, and prevention in Africa. Circulation. 2013;112(23):3584-3591.

3. Reményi B, Wilson N, Steer A, et al. World Heart Federation criteria for echocardiographic diagnosis of rheumatic heart disease - an evidence-based guideline. Nat Rev Cardiol. 2012;9(5):297-309. doi:10.1038/nrcardio.2012.7

4. Walsh W, Brown A, Carapetis J, et al. The diagnosis and management of chronic rheumatic heart disease - an Australian Guideline: review. Heart Lung Circ. 2008;17(4):271-289. doi:10.1016/j. hlc.2007.12.002

5. Zu"hlke L, Engel ME, Karthikeyan G, et al. Characteristics, complications, and gaps in evidence-based interventions in rheumatic heart disease: the global rheumatic heart disease registry (the REMEDY study). Heart. 2015;36(18):1115-1122.

6. Lumsden RH, Akwanalo C, Chepkwony S, et al. Clinical and geographic patterns of rheumatic heart disease in outpatients attending cardiology clinic in western Kenya. Int J Cardiol. 2016;223:228-235.

7. Rwebembera J, Manyilirah W, Zhu ZW, et al. Prevalence and characteristics of primary left-sided valve disease in a cohort of 15,000 patients undergoing echocardiography studies in a tertiary hospital in Uganda. BMC Cardiovasc Disord. 2018;18(1):1-12.

8. Abdissa SG, Oli K, Feleke Y, Yadeta D. Spectrum of cardiovascular diseases among Ethiopian patients at Tikur Anbessa Specialized University Teaching Hospital, Addis Ababa. Ethiop Med J. 2014;52 (1):9-17.

9. Melka A. Rheumatic heart disease in Gondar College of Medial Sciences Teaching Hospital: socio-demographic and clinical profile. Ethiop Med J. 1996;34(4):207-216.

10. Jimma University. Jimma University Medical Center Inaugurated; 2018.Available from: https://www.ju.edu.et/?q=article/specializedhosptial. accessed Spetember 29, 2020. 
11. Gardin JM. American Society of Echocardiography: recommendations for a standardized report for adult transthoracic echocardiography. J Am Soc Echocardiogr. 2002;15:275-290.

12. Nishimura RA, Otto CM, Bonow RO, et al. 2014 AHA/ACC guideline for the management of patients with valvular heart disease: executive summary: a report of the american college of cardiology/ american heart association task force on practice guidelines. $J \mathrm{Am}$ Coll Cardiol. 2014;129(23):252-289.

13. Bonow RO, Carabello BA, Chatterjee K, et al. 2008 Focused update incorporated into the ACC/AHA 2006 guidelines for the management of patients with valvular heart disease: a report of the American College of Cardiology/American Heart Association Task Force on Practice Guidelines (writing committee to revise the 1998 guidelines for the management of patients with valvular heart disease) endorsed by the society of cardiovascular anesthesiologists, society for cardiovascular angiography and interventions, and society of thoracic surgeons. Circulation. 2008;118(15):e1-42.

14. Mirabel M, Tafflet M, Noël B, et al. Newly diagnosed rheumatic heart disease among indigenous populations in the Pacific. Heart. 2015;101(23):1901-1906.

15. Frank JE, Jacobe KM. Evaluation and management of heart murmurs in children. Am Fam Physician. 2011;84(7):793-800.

16. Okello E, Longenecker CT, Beaton A, Kamya MR, Lwabi P. Rheumatic heart disease in Uganda: predictors of morbidity and mortality one year after presentation. BMC Cardiovasc Disord. 2017;17(1):1-10. doi:10.1186/s12872-016-0451-8
17. Sani MU, Karaye KM, Borodo MM. Prevalence and pattern of rheumatic heart disease in the Nigerian savannah: an echocardiographic study. Cardiovasc J Afr. 2007;18(5):295-299.

18. Yadeta D, Hailu A, Haileamlak A, et al. Prevalence of rheumatic heart disease among school children in Ethiopia: A multisite echocardiography-based screening. Int J Cardiol. 2016;221:260-263. doi:10.1016/j.ijcard.2016.06.232

19. Aurakzai HA, Hameed S, Shahbaz A, et al. Echocardiographic profile of rheumatic heart disease at a tertiary cardiac centre. J Ayub Med Coll Abbottabad. 2009;21(3):122-126.

20. Tadele H, Mekonnen W, Tefera E. Rheumatic mitral stenosis in Children: more accelerated course in sub-Saharan patients. BMC Cardiovasc Disord. 2013;13(1):1. doi:10.1186/1471-226113-95

21. Lubega S, Aliku T, Lwabi P. Echocardiographic pattern and severity of valve dysfunction in children with rheumatic heart disease seen at Uganda Heart Institute, Mulago hospital. Afr Health Sci. 2014;14 (3):617-625.

22. Wood AD, Mannu GS, Clark AB, Tiamkao S, Kongbunkiat K, Bettencourt-silva JH. Rheumatic mitral valve disease is associated with worse outcomes in stroke a thailand national database study. Am Heart Assoc. 2016;47(11):2695-2701.
Open Access Rheumatology: Research and Reviews

\section{Publish your work in this journal}

Open Access Rheumatology Research and Reviews is an international, peer-reviewed, open access journal publishing original research, reports, editorials, reviews and commentaries on all aspects of clinical and experimental rheumatology in the clinic and laboratory including the following topics: Pathology, pathophysiology of rheumatological diseases; Investigation, treatment and management

\section{Dovepress}

of rheumatological diseases; Clinical trials and novel pharmacological approaches for the treatment of rheumatological disorders. The manuscript management system is completely online and includes a very quick and fair peer-review system, which is all easy to use. Visit http://www.dovepress.com/testimonials.php to read real quotes from published authors. 